\title{
Freezing Points of Cobalt and Nickel
}

\author{
By Milton S. VanDusen and Andrew I. Dahl
}

\begin{abstract}
The freezing points of nickel and cobalt on the International Temperature Scale have been determined on samples from the same lots of metal used by Day and Sosman in their freezing-point determinations on the gas-thermometer scale. The freezing temperatures on the International Temperature scale are

Nickel_
Cobalt $\ldots \ldots$

A value of the constant $C_{2}$ in Wien's (or Planck's) radiation law has been calculated on the basis of the observed ratios of brightness of black bodies at the freezing points of nickel and gold, cobalt and gold, and palladium and gold, and the values of the freezing temperatures of these metals on the thermodynamic scale as derived from the work of Day and Sosman. The average value of $C_{2}$ was computed to be $1.438 \mathrm{~cm}$ degrees.
\end{abstract}

\section{Introduction}

The International Temperature Scale ${ }^{1}$ adopted in 1927 by the Seventh General Conference of Weights and Measures is based on a number of fixed points, the temperatures of which have been defined. The highest temperature so defined is that of the gold point, namely, $1,063^{\circ} \mathrm{C}$. Above the gold point the temperature scale is extended on the basis of Wien's law of radiation. Any temperature, $t$, is determined by the ratio of intensity $J_{2}$ of monochromatic visible radiation of wavelength $\lambda \mathrm{cm}$, emitted by a black body at temperature $t$, to the intensity $J_{1}$ of radiation of the same wavelength emitted by a black body at gold point, by means of the equation

$$
\log _{e} \frac{J_{2}}{J_{1}}=\frac{C_{2}}{\lambda}\left(\frac{1}{1336}-\frac{1}{t+273}\right) .
$$

The constant $C_{2}$ is taken as $1.432 \mathrm{~cm}$ degrees and must be such that $\lambda(t+273)$ is less than $0.3 \mathrm{~cm}$ degree.

The assignment of the value $1,063^{\circ} \mathrm{C}$ to the gold point is based largely upon the gas-thermometer work of Holborn and Day ${ }^{2}$ and Day and Sosman. ${ }^{3}$

Day and Sosman extended the constant-volume nitrogen thermometer scale up to $1,550^{\circ} \mathrm{C}$ by obtaining the temperatures of various fixed points, including the freezing points of copper, nickel,

1 G. K. Burgess, BS J. Research 1, 635 (1928) RP22

${ }_{2}^{2}$ L. Holborn and A. Day, Am. J. Sci. 10, 17 (1900).

3 A. Day and R. B. Sosman, Carnegie Inst. Wash. Pub. 157 (1911). cobalt, and palladium. The authors were very fortunate to have available for the present work samples of nickel and cobalt from the same lots of these materials that were used by Day and Sosman in their gas-thermometer work. Thus by obtaining the freezing points of these materials on the International Temperature Scale it was possible to compare the temperature scales at these points. The purity of the samples of nickel and cobalt was such as to give a positive significance to freezing-point determinations of these materials.

\section{Previous Work on the Freezing Points of Nickel and Cobalt}

With the exception of the determination of the nickel point by Wensel and Roeser, ${ }^{4}$ practically no work has been done during the past 30 years on the freezing points of nickel and cobalt. Most of the early determinations were made by means of thermocouples, and the conversion of the reported values to the International Temperature Scale is uncertain. With the exception of the gas-thermometer work by Day and Sosman, the early work on nickel and cobalt is for the most part of historical interest only. The values for the freezing points of nickel and cobalt are summarized in table 1 .

Where sufficient information was given, the reported values were adjusted to the International Temperature Scale.

\footnotetext{
${ }^{4}$ H. T. Wensel and Wm. F. Roeser, BS J. Research 5; 1309 (1930) RP258.
} 
TABLE 1.-Summary of determinations of freezing points of nickel and cobalt

\begin{tabular}{|c|c|c|c|c|}
\hline Observer & Date & Method & $\begin{array}{c}\text { Report- } \\
\text { ed } \\
\text { value }\end{array}$ & $\begin{array}{l}\text { Ad- } \\
\text { justed } \\
\text { value }\end{array}$ \\
\hline \multicolumn{5}{|c|}{ NICKEL } \\
\hline & & & $\circ C$ & $\circ C$ \\
\hline Holborn and Wien ${ }^{3}$ & 1895 & Thermocouple... & 1,484 & (n..... \\
\hline Harker b & 1905 & $\ldots$ _. do & 1,427 & $-\ldots$ \\
\hline Copaux c ${ }^{\circ} \ldots$ & 1905 & - do & 1,470 & $\ldots$ \\
\hline Burgess d . . . . & 1907 & Optical pyrometer....... & 1,435 & 1,445 \\
\hline Day and sosman e....... & 1911 & Gas thermometer.... & 1,452 & $-\ldots$ \\
\hline Wensel and Roeser ${ }^{f} \ldots \ldots$ & 1930 & Optical pyrometer....... & 1.455 & 1,455 \\
\hline VanDusen and Dahl...... & 1947 & _-_... do do......... & 1,455 & 1,455 \\
\hline \multicolumn{5}{|c|}{ COBALT } \\
\hline Copaux c & 1005 & Thermocouple & 1,530 & 1,526 \\
\hline Burgess d & 1907 & Optical pyrometer.. & 1,464 & 1,475 \\
\hline Day and Sosman e....... & 1911 & Gas thermometer........ & 1,490 & - $-\cdots$ \\
\hline Raydt and Tammann $\mathrm{g}_{. .}$ & 1913 & Thermocouple & 1,480 & 1,484 \\
\hline Ruer and Kaneko h....... & 1913 & _._. do & 1,491 & 1,495 \\
\hline Burgess and Waltenberg i & 1914 & Microoptical pyrometer & 1,478 & 1,482 \\
\hline VanDusen and Dahl & 1947 & $\begin{array}{ll}-1 \\
-1\end{array}$ & 1,495 & 1,495 \\
\hline
\end{tabular}

s L. Holborn and W. Wien, Wied. Ann. 56, 360 (1895).

b J. A. Harker, Proc. Royal Soc. (London) [A] 76, 235 (1905).

e H. Copaux, Compt, rend, 140, 657 (1905).

d G. K. Burgess, Bul. BS 3, 345 (1907) S62.

e A. Day and R. B. Sosman, Carnegie Inst. Wash. Pub. 157 (1911).

i H. T. Wensel and Wm. F. Roeser, BS J. Research 5, 1309 (1930) RP 258.

z U. Raydt and G. Tammann, Z. anorg. Chem. \$3, 446 (1913).

h R. Ruer and K. Kaneko, Ferrum 11, 5 (1913-14).

i G. K. Burgess and R. G. Waltenberg, Bul. BS 10, 79 (1914) S205.

\section{Materials}

A detailed discussion giving the sources and the analyses of the metals used by Day and Sosman in their gas-thermometer work is given in their book, page 85 . The analyses of the nickel and cobalt ingots made at the conclusion of the present work are shown in table $2 .^{5}$

The compositions were essentially the same as those originally reported by Allen of the Geophysical Laboratory, with the exception of the iron

TABLE 2.-Results of analyses

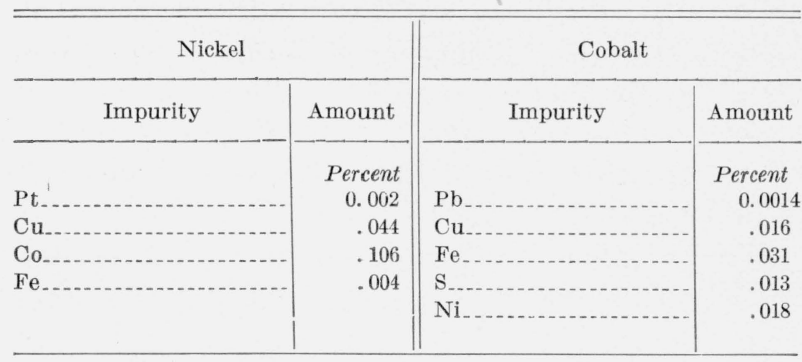

${ }^{5}$ Analyses made by R. K. Bell, of the Chemistry Division of this Bureau. content of the cobalt. A test for iron in a sample of cobalt that had not been used in the freezingpoint determinations gave only 0.004 percent of iron. This indicated that the cobalt had become slightly contaminated with iron during drilling operations for the installation of sight tubes. This iron content, however, will not affect the freezing point of cobalt to any significant extent.

\section{Present Work}

\section{General Procedure}

The so-called crucible method was followed in the freezing-point determinations. In this method a hollow enclosure or black body is immersed in a bath of the metal, and observations on the radiation from the black body are made with an optical pyrometer during the time the metal is freezing. In the present work the melting was done by means of a high-frequency induction furnace. This type of heating provides for a high degree of temperature uniformity throughout the sample and minimizes the probability of contamination of the sample by the furnace elements.

\section{Crucibles}

Previous use of beryllia and thoria as crucible and sight tube materials for melting pure metals led to their use in the present work. Thoria proved to be more satisfactory because of its greater mechanical strength. The beryllia and thoria crucibles and accessory parts were prepared by the general method described by Swanger and Caldwell. ${ }^{6}$ The crucible and the sight tube were always of the same material.

\section{Atmosphere}

As both nickel and cobalt oxidize readily at high temperatures, it was necessary to melt the metals in either an inert or a reducing atmosphere. Atmospheres of hydrogen ${ }^{7}$ and nitrogen (see footnote 3), as well as vacuum (see footnote 4) have been used by previous investigators. Helium was chosen for the present work as all available evidence indicates that the solubility of helium in either nickel or cobalt is less than that of hydrogen or nitrogen. The helium was sufficiently freed of oxygen to prevent any visible oxidation

\footnotetext{
${ }^{6} \mathrm{Wm}$. H. Swanger and F. R. Caldwell, BS J. Research 6, 1131 (1931) RP 327.

${ }^{7}$ G. K. Burgess and R. G. Waltenberg, Bul. BS 10, 79 (1914) S205.
} 
of the freezing point samples. Commercial helium was passed through copper chips heated at about $750^{\circ} \mathrm{C}$ to remove oxygen and then through magnesium perchlorate and phosphorus pentoxide to remove water vapor.

For comparison purposes, the freezing temperatures of nickel and cobalt were also measured in vacuum.

\section{Arrangement of Apparatus}

Figure 1 shows a cross-sectional view of the crucible assembly. The samples of nickel and cobalt were formed into the proper shape by melting them in beryllia crucibles of the size and shape to be used in the freezing-point determinations. Each sample weighed about 80 g.
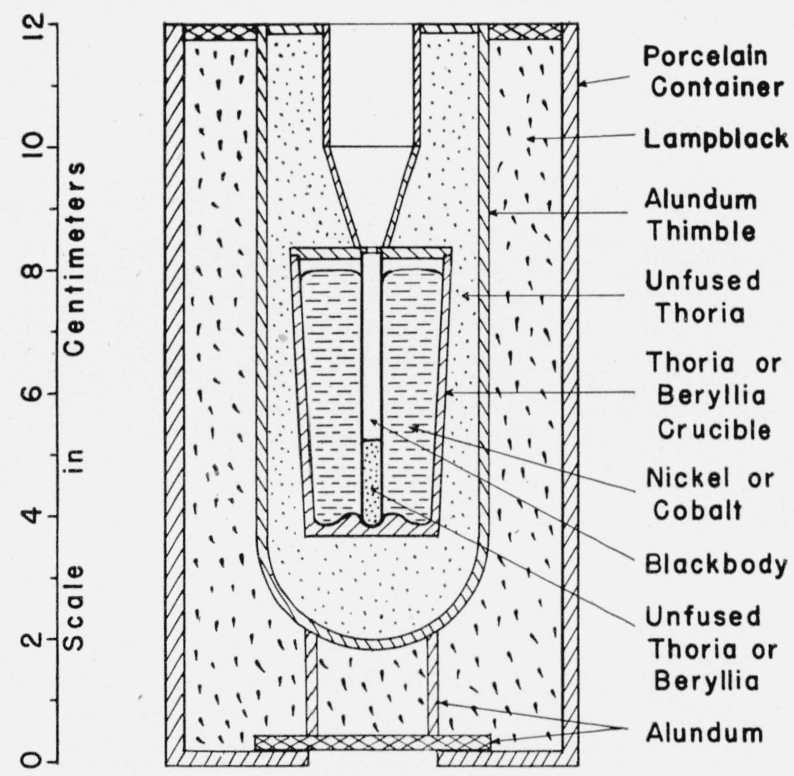

Figure 1. Crucible assembly.

An axial hole was drilled in each ingot to accommodate the sight tube. Each sample, together with its sight tube, was placed in a refractory-oxide crucible and mounted in a larger porcelain container, as shown in figure 1 . The relatively coarse insulating material surrounding the crucible permitted the passage of gas around the sample, and the lampblack provided excellent heat insulation. The assembly shown in figure 1 was placed inside a Pyrex-glass enclosure, shown in figure 2 , in which the desired atmosphere could be maintained. The tube was closed at the top with a Pyrex

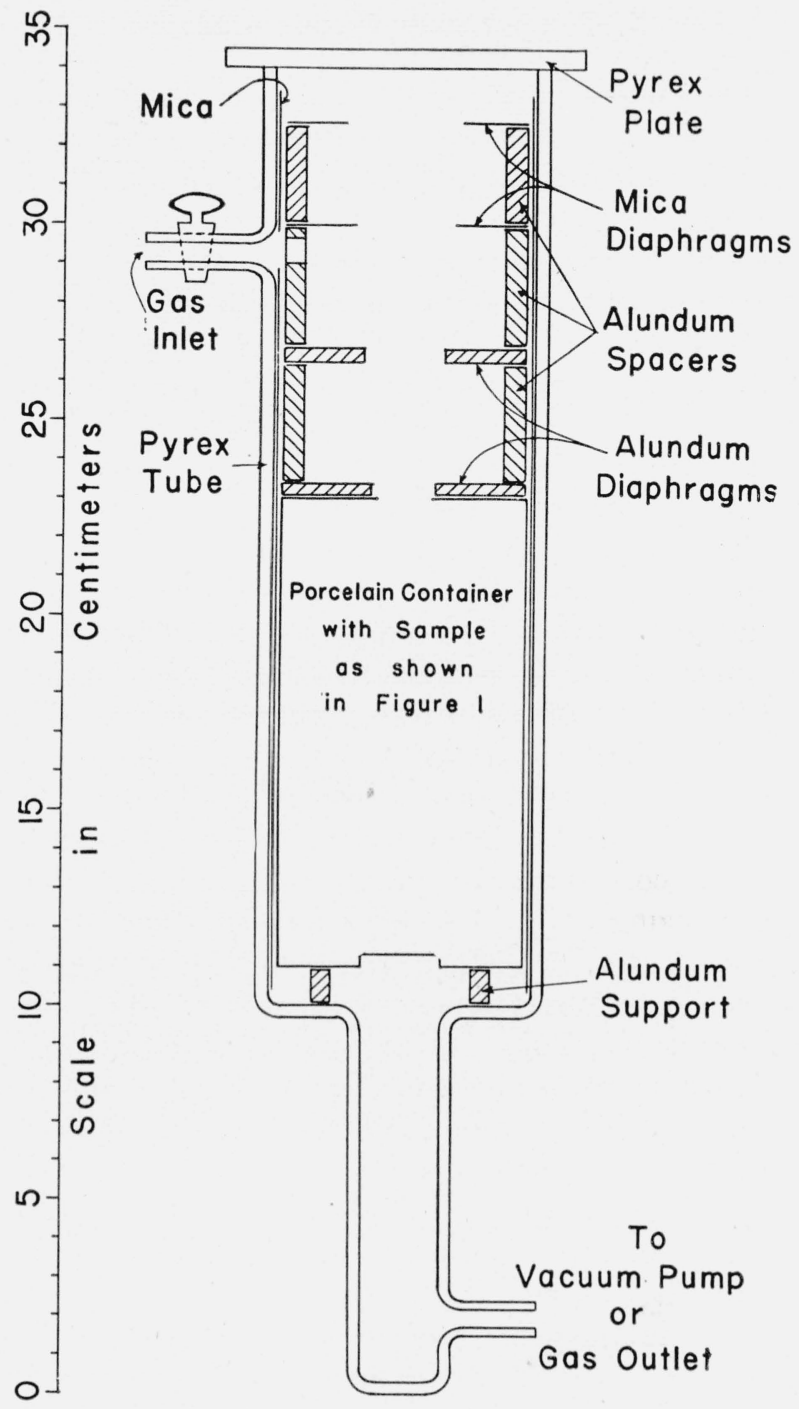

Figure 2. Crucible assembly in Pyrex envelope.

window sealed to the tube with propylene phthalate. The Pyrex tube fitted closely inside the water-cooled coil of the induction furnace.

In the experiments employing a helium atmosphere, the gas was passed slowly through the Pyrex enclosure for about 16 hours before the heating was begun as well as during the actual heating. For the experiments in vacuum the pressure within the enclosure was maintained between 0.001 and $0.005 \mathrm{~mm}$ of $\mathrm{Hg}$ by means of a mercury diffusion pump. A liquid-air trap was located between the diffusion pump and the Pyrex tube to prevent mercury vapor from diffusing back into the tube. 


\section{Temperature Measurements}

The optical pyrometer used was designed by Fairchild and Hoover. ${ }^{8}$ It was fitted with a 45 degree total-reflecting for sighting into the black body. Two pyrometer lamps were used in the present work. For observations on the black body at the gold point, an assembly of the same dimensions as that shown in figure 1 was used. The difference was that only lamp-black insulation was used, and the crucible and sight tube were made of graphite.

The brightness ratio, $J_{2} / J_{1}$, was measured by utilizing a sector disk. The sector had two openings and was made by mounting steel strips on an aluminum disk. The edges of the strips were ground or lapped, straight and alined to be radial with the aid of a circular dividing engine. The transmission of the sector was 2.625 percent as computed from the measurement of the openings with a circular dividing engine. The sector transmission corresponded to a ratio of brightness from the freezing point of nickel to about $1,069^{\circ} \mathrm{C}$ for $\lambda_{e}=0.6533 \mu$, the effective wavelength of the red screen over this temperature interval. Also, the sector transmission corresponded to a ratio of brightness from the freezing point of cobalt to about $1,093.5^{\circ} \mathrm{C}$ for $\lambda_{e}=0.6531 \mu$, the effective wavelength of the red screen over the temperature interval in question. The values of $1,069^{\circ}$ and $1,093.5^{\circ} \mathrm{C}$ were obtained from observations of the lamps at the gold point and a knowledge of the current temperature relation of the lamps over the temperature intervals involved.

In addition to using a sector disk as mentioned above, an absorption glass was used to obtain temperature measurements at the freezing points of the metals. This absorption glass has been calibrated repeatedly by comparison with sector disks over a period of about 20 years, and its calibration is considered well established.

A total of about 60 freezes on each metal were made, with both authors serving as observers. The average number of pyrometer settings during one freeze was seven. About 10 freezes on each metal were made with the samples in vacuum and the remainder with the samples in helium. No significant difference was noted. Both nickel and cobalt exhibited some undercooling. In a particular cobalt freeze, the metal was observed to under-

${ }^{8}$ C. O. Fairchild and W. H. Hoover, J. Opt. Soc. Am. 7, 543 (1923). cool about 60 degrees before solidification started. It was possible to limit the magnitude of the undercooling by slightly jarring the furnace coil when the desired temperature was reached. An undercool of about 5 to 10 degrees was usually obtained.

As the transmission of the sector was such as to produce a match when the lamps were operated not exactly at the gold point $\left(1,063^{\circ} \mathrm{C}\right)$ but at neighboring temperatures, the working equation becomes:

$$
\log _{e} \frac{J_{2}}{J_{0}}=\log _{e} T=\frac{C_{2}}{\lambda_{e}}\left(\frac{1}{t_{0}+273}-\frac{1}{t_{2}+273}\right),
$$

where $T$ is the transmission of the sector.

If logarithms to the base 10 are used and $C_{2}$ is expressed in micron degrees, the above equation may be written

$$
\frac{1}{t_{2}+273}=\frac{1}{t_{0}+273}+\frac{\log _{10} T}{14320 x 0.43429} .
$$

For a particular set of observations at the nickel point, $t_{0}=1068.9^{\circ} \mathrm{C}$. Substituting in eq 3 , where $\lambda_{e}=0.6533$ and $T=0.02625$, we have $t_{2}=1455.2^{\circ} \mathrm{C}$. For a particular set of observations at the cobalt point, $t_{0}=1093.6^{\circ} \mathrm{C}$. Substituting in eq 3 , where $\lambda_{\varepsilon}=0.6531$ and $T=0.02625$, we have $t_{2}=1494.7^{\circ} \mathrm{C}$. A summary of the observational data is listed in table 3 .

TABLE 3.-Summary of determinations of the freezing

\begin{tabular}{|c|c|c|c|c|c|}
\hline \multirow[b]{2}{*}{$\begin{array}{l}\text { Lamp } \\
\text { number }\end{array}$} & \multirow[b]{2}{*}{ Absorption device } & \multicolumn{2}{|c|}{ Nickel } & \multicolumn{2}{|c|}{ Cobalt } \\
\hline & & $\begin{array}{l}\text { Number } \\
\text { of freezes }\end{array}$ & $\begin{array}{l}\text { A verage } \\
\text { value of } \\
\text { freezing } \\
\text { point }\end{array}$ & $\begin{array}{l}\text { Number } \\
\text { of freezes }\end{array}$ & $\begin{array}{l}\text { Average } \\
\text { value of } \\
\text { freezing } \\
\text { point }\end{array}$ \\
\hline $\mathrm{F}-16 \ldots$ & Glass No. $1 \ldots \ldots$ & 10 & $1,455.0$ & 22 & $1,494.7$ \\
\hline F-16 & Sector No. 2 & 29 & $1,455.3$ & 13 & $1,494.8$ \\
\hline $\mathrm{L}-1 \ldots \ldots$ & Glass No. $1 \ldots$ & 18 & $1,455.3$ & 22 & $1,494.4$ \\
\hline L-1........... & Sector No. $2 \ldots$ & 7 & $1,455.0$ & 4 & $1,495.3$ \\
\hline \multicolumn{2}{|c|}{ Weighted mean } & & $1,455.2$ & & $1,494.7$ \\
\hline
\end{tabular}
points of nickel and cobalt

An estimate of the errors entering into the measurement of the freezing temperatures of nickel and cobalt are given in table 4 .

In view of the estimated uncertainties, the values of the freezing points of the samples of nickel and cobalt have been rounded to $1,455^{\circ} \mathrm{C}$ for nickel and $1,495^{\circ} \mathrm{C}$ for cobalt, with an uncertainty of $1^{\circ} \mathrm{C}$. 
TABLE 4.-Estimate of uncertainties

\begin{tabular}{|c|c|c|}
\hline \multirow{2}{*}{ Source } & \multicolumn{2}{|c|}{$\begin{array}{l}\text { Equivalent in } \\
\text { deg C, with- }\end{array}$} \\
\hline & Sector & Glass \\
\hline Transmission of sector...... & 0.1 & \\
\hline Effective wavelength & .3 & \\
\hline Calibration of absorption glass.... & $-\ldots$ & 0.8 \\
\hline Photometric matching. & .3 & .3 \\
\hline Departure from black-body conditions & .2 & .2 \\
\hline Maximum, if all are of the same sign ........ & 0.9 & 1.3 \\
\hline
\end{tabular}

The ratios of brightness, $R$, of black bodies at the freezing point of nickel and cobalt to a black body at the gold point may be obtained by substituting in the equation

$$
\log _{10} R=\log _{10} \frac{J_{l}}{J_{A u}}=\frac{C_{2} \log _{10} e}{\lambda_{e}}\left(\frac{1}{1336}-\frac{1}{t-273}\right) .
$$

For nickel, where $\lambda_{e}=0.6533, R=41.40$. For cobalt, where $\lambda_{e}=0.6532, R=54.99$.

\section{Calculation of the value of $\mathrm{C}_{2}$ in Planck's law of radiation}

Using the values of the freezing points of gold, vickel, and cobalt as determined by Day and Sosman, and the above values of the ratios of brightness, values of the constant $C_{2}$ in Planck's law of radiation can be calculated. For simplicity, Wien's law is used in the calculations as it yields the same values as those computed from Planck's law in the temperature range investigated. As the values of Day and Sosman for the temperatures of the various fixed points are on the constant-volume nitrogen scale, small corrections are necessary to convert them to the thermodynamic scale. ${ }^{9}{ }^{10}$ Wien's law yields the following expression for $C_{2}$

$$
C_{2}=\frac{\lambda_{e} \log _{e} \frac{J_{t}}{J_{A u}}}{\frac{1}{1336}-\frac{1}{t+273}} .
$$

In addition to the samples of nickel and cobalt

9 E. Buckingham, Bul. BS 3, 237 (1907) S57.

10 F. G. Keyes, Temperature, its measurement and control in science anp industry, p. 45 (Reinhold Publishing Corp., New York, N. Y., 1941). used in the present work, Fairchild, Hoover, and Peters $^{11}$ have measured $J_{t} / J_{A u}$, for a sample of palladium that was compared with the palladium used by Day and Sosman and found to have the same freezing point to within $0.1^{\circ} \mathrm{C}$. Table 5 lists the values of $C_{2}$ as derived from these points.

TABLE 5.-Values of $C_{2}$ based on optical and gas ther-

\begin{tabular}{|c|c|c|c|c|}
\hline Fixed point & $\begin{array}{l}\text { Tempera- } \\
\text { ture a } \\
\text { (Day and } \\
\text { Sosman } \\
\text { gas scale) }\end{array}$ & $\begin{array}{l}\text { Thermo- } \\
\text { dynamic } \\
\text { scale }\end{array}$ & $\log _{\theta} \frac{J_{t}}{J_{A u}} \times 10^{7}$ & $C_{2}$ \\
\hline $\mathrm{Au}$ & $\begin{array}{l}{ }^{\circ} \mathrm{C} \\
1062.4\end{array}$ & $\begin{array}{l}{ }^{\circ} \mathrm{C} \\
1062.6\end{array}$ & & $\mathrm{~cm}$ degrees \\
\hline $\mathrm{Ni}$ & 1452. 7 & 1453.1 & 2,433 & 1. 4364 \\
\hline $\mathrm{Co}$ & 1490.6 & 1491.0 & 2,618 & $1439_{6}$ \\
\hline \multirow[t]{2}{*}{$\mathrm{Pd}$} & 1549.4 & 1549.8 & 2,879 & 1. $438_{2}$ \\
\hline & & & Mean........ & 1. $438_{2}$ \\
\hline
\end{tabular}
mometry

a These values are the unweighted means of the individual determinations of Day and Sosman and are slightly different from the weighted means reported by them.

Since the adoption of the International Temperature Scale in 1927 there has been considerable evidence to indicate that the value of 1.432 assigned to $C_{2}$ is low. The International Conference of Weights and Measures was scheduled to consider revision of the temperature scale in 1939 but failed to meet because of the unsettled political conditions. One of the proposed revisions was to increase the value of $C_{2}$ to $1.436 \mathrm{~cm}$ degrees. Since 1939 there has been evidence that the value should be still higher.

A value of the constant $C_{2}$ may be arrived at by a number of methods. Wensel ${ }^{12}$ discusses these methods and summarizes the values of $C_{2}$ as obtained from the various sources.

The particular value of $C_{2}$ that was given the greatest weight was that derived from the atomic constants. In the most recent summary of the physical constants, Birge ${ }^{13}$ gives a value of $1.4384_{8} \mathrm{~cm}$ degrees for $C_{2}$.

Washington, June 6, 1947.

11 C. O. Fairchild, W. H. Hoover, and M. F. Peters, BS J. Research 2, 931, (1929) RP65.

${ }^{12}$ H. T. Wensel Jour. Research NBS 22, p. 375 (1939) RP1189.

${ }^{13}$ R. T. Birge, Rev. Modern Phys. 13, 233, (1941). 